* Mestranda pelo Programa de Pós-Graduação Stricto Sensu em Direito Constitucional da Universidade de Fortaleza (UNIFOR). Pós-graduada em Direito e Processo do Trabalho pela Universidade de Fortaleza (UNIFOR). Professora Universitária.

** Doutora em Direito pela Universidade de São Paulo. Pós-Doutorado na School of Industrial and Labor Relations da Cornell University. LL.M na Faculdade de Direito da University of Toronto. Graduada em Direito pela Universidade Federal do Ceará. Professora do Programa de Pós-Graduação em Direito Constitucional e do Curso de Direito da Universidade de Fortaleza (UNIFOR).

\section{Discriminação Nas Relações De Trabalho Em Virtude da Coleta de Dados Sensíveis}

Labour Relations' Discrimination Due
To The Collection Of Sensitive Data

Andréa Dourado Costa* Ana Virginia Moreira Gomes**

Como citar: COSTA, Andréa Dourado; GOMES, Ana Virginia Moreira. Discriminação nas relações de trabalho em virtude da coleta de dados sensíveis. Scientia Iuris, Londrina, v. 21, n. 2, p. 214-236, jul. 2017. DOI: $10.5433 / 2178-8189.2017 \mathrm{v} 21 \mathrm{n} 1 \mathrm{p} 214$. ISSN: 2178-8189.

Resumo: Este estudo visa examinar os limites no exercício do poder diretivo do empregador diante da potencial violação dos direitos de personalidade dos empregados pela prática de atos discriminatórios a partir da coleta de dados sensíveis. A pesquisa analisa o conceito de privacidade, bem como identifica as consequências decorrentes da evolução tecnológica, que possibilitaram o aperfeiçoamento de instrumentos de coletas de dados e do tratamento de informações, em especial no que concerne às suas consequências nas relações de trabalho. A seguir, o estudo examina o direito de privacidade do trabalhador a partir da concepção de autodeterminação informativa, considerando a Convenção $\mathrm{n}^{\mathrm{o}} 111$ 
da OIT, normas nacionais e decisões judiciais. A pesquisa conclui que o direito do trabalho ainda não assegura a tutela eficaz aos dados sensíveis do trabalhador nas relações empregatícias. $\mathrm{O}$ desenvolvimento da pesquisa se dá por meio de pesquisa bibliográfica e documental. Trata-se, por conseguinte, de uma pesquisa qualitativa e exploratória.

Palavras-chave: Privacidade. Relação de emprego. Discriminação. Dados sensíveis. Autodeterminação informativa.

Abstract: This study examines limits in the use of an employer's power in relation to the potential violation of an employee's personal rights as the former can practice discriminatory acts from the collection of sensitive data. Furthermore, this research analyzes the concept of privacy, as well as identifies the consequences of modern technological evolution, which has enabled the development of instruments for data collection and information processing, specifically studying their consequences in labor relations. This study then examines the worker's right to privacy based on the concept of self-determination, taking into account ILO Convention 111, national standards, and judicial decisions. In the end, this research concludes that this labor law still does not ensure an effective protection of sensitive data concerning the employee in employment relations. This research used the bibliographic and documental method; this is, therefore, a qualitative and 


\section{exploratory study.}

Keywords: Privacy. Employment relationship. Discrimination. Sensitive data. Informational self-determination. 


\section{INTRODUÇÃO}

$\mathrm{O}$ direito à privacidade foi inicialmente definido como o "direito a estar só", sob uma lógica puramente proprietária, de proteção a invasões externas na vida privada do indivíduo, limitado à sua intimidade, esfera mais ampla da privacidade. A partir da introdução de novas tecnologias, o conceito de privacidade foi sendo transformado para se adequar à necessidade da sociedade do século XXI, em que as pessoas são representadas pelas suas informações, pois, em diversas situações da vida, inclusive no trabalho, são essas informações que as definem.

A finalidade de ser deixado só foi sendo substituída pela necessidade de autodeterminação informativa, ou seja, do indivíduo assumir um papel ativo no fornecimento dos seus próprios dados, por meio do controle sobre a exatidão das suas informações, sobre quem as opera e sobre a finalidade para a qual foram coletadas, visto que parte dessas informações é de cunho pessoal, ou seja, dizem respeito unicamente ao titular das informações.

$\mathrm{O}$ avanço da tecnologia e a crescente possibilidade de acesso a informações impõem a necessidade de controle sobre dados pessoais a fim de se garantir os direitos de personalidade diante do aumento desenfreado das informações coletadas por instituições públicas e privadas. É nesse contexto que se coloca a necessidade de ampliação do conceito tradicional de privacidade, para incluir a necessidade de uma proteção mais ampla e eficaz da circulação das informações pessoais.

A evolução tecnológica de busca de informações e tratamento de dados alcançou as relações entre particulares, em especial, as relações trabalhistas. Os empregadores passaram a se utilizar de instrumentos informatizados para obter dados sobre os candidatos a vagas de emprego, 
bem como sobre seus empregados. Destarte, esses dados incluem os chamados dados sensíveis, que dizem respeito, por exemplo, à orientação sexual do trabalhador, questões de opinião política, religiosa e sindical, e que não podem ser coletados e muito menos divulgados sem o consentimento do trabalhador.

O empregador que se utiliza desses dados, discriminando o trabalhador a partir do acesso a informações pessoais, dentro e fora do ambiente de trabalho, pode acreditar estar apoiado no legítimo exercício do poder diretivo; porém o poder diretivo do empregador não é absoluto e deve respeitar os direitos constitucionais de personalidade e dignidade da pessoa humana do trabalhador. A discriminação contra o empregado pode ocorrer entre chefe e subordinado, bem como entre colegas de trabalho e entre trabalhador e cliente, prejudicando sobremaneira o desenvolvimento da personalidade do trabalhador.

Este estudo visa examinar os limites que devem ser observados pelo empregador no exercício do poder diretivo diante da potencial violação dos direitos de personalidade dos empregados e da prática de atos discriminatórios pelo empregador a partir da coleta de dados sensíveis. Faz-se necessário, portanto, discorrer sobre o direito constitucional de privacidade inserido no contexto da relação empregatícia e o tratamento dado às informações fornecidas pelos candidatos a emprego e empregados de uma empresa. Por fim, importa ao presente texto, averiguar o tratamento dado pela jurisprudência ao assunto, diante de atos de discriminação praticados pelos empregadores no ambiente de trabalho.

O desenvolvimento do estudo se dá por meio de pesquisa bibliográfica, referências doutrinárias já publicadas por intermédio de escritos e eletrônicos, tais como livros, artigos científicos e páginas de web sites. Trata-se, por conseguinte, de uma pesquisa qualitativa e 
exploratória.

\section{EVOLUÇÃO DO CONCEITO DE PRIVACIDADE: DO DIREITO A ESTAR SÓ AO DIREITO ÀAUTODETERMINAÇÃO INFORMATIVA}

O conceito de privacidade surgiu com a desagregação da sociedade feudal, pois, até então, poucos tinham o privilégio de se isolar. A partir da desagregação, a possibilidade de se isolar se estendeu a quem tinha meios materiais para tanto. Vários fatores foram fundamentais para satisfazer essa necessidade de intimidade - das novas técnicas de construção das habitações à separação entre o local onde se vive e o local de trabalho. Ou seja, uma possibilidade da classe burguesa, que consegue realizá-la através das transformações socioeconômicas da Revolução Industrial (RODOTÁ, 2008, p. 26). Nesse sistema jurídico burguês, os direitos da personalidade foram reconhecidos por via da garantia que se dava à propriedade.

Vê-se, portanto, que a privacidade não nasceu de uma exigência natural de cada um, mas de um privilégio de determinados grupos que, por meio do poder patrimonial, exerciam seu direito de personalidade.

Em 1890, Warren e Brandeis (1890, p. 195) definiram o direito à privacidade como "o direito de estar só". Como os autores explicam, "todos os homens têm o direito de evitar a curiosidade popular acerca de alguns aspectos da sua vida, seja na vida pública ou não, enquanto outros são apenas privados porque as pessoas em causa não assumiram uma posição que torna legítimas as questões de investigação pública" (WARREN; BRANDEIS, 1890, p. 216). A tutela da privacidade se restringia à intimidade do indivíduo, sendo essa a esfera mais ampla da 
privacidade, de alcance apenas àquelas pessoas mais próximas ao titular, mas também alcançava a esfera do segredo, que caberia apenas ao seu titular ter acesso.

Esse conceito tradicional evoluiu. O indivíduo, ao longo do tempo, foi percebendo que quanto mais informações ele adquiria, mais vantagens ele tinha sobre os demais, no seu modo de viver, no trabalho, na comunicação entre as pessoas. E, com isso, constatou que o armazenamento e uso adequado dessas informações lhe conferiria maior poder sobre os outros.

A partir das novas tecnologias, dos recursos a computadores, os instrumentos de coletas de dados e de informações foram se aperfeiçoando, fazendo surgir novas dimensões que ocasionaram um apelo maior à privacidade, mas não no seu sentido tradicional, isto é, de defesa da esfera privada contra as invasões exteriores, sob uma lógica proprietária, e sim da possibilidade de indivíduos e grupos controlarem suas próprias informações de forma integrada. Essas informações estão ligadas à necessidade incessante de dados pelas instituições públicas e privadas, retratando uma verdadeira progressão das formas de controle social. Acentua-se que, nas definições tradicionais, a privacidade representava um mero instrumento para alcançar a finalidade de ser deixado só e foi sendo substituído pela necessidade de autodeterminação informativa.

O direito à autodeterminação informativa importa na assunção de um papel ativo no fornecimento de dados, em que se possibilita o exercício de um real controle pelo indivíduo sobre a exatidão de suas informações, sobre quem as opera e sobre a finalidade para a qual foram coletados, uma vez que a maior parte dessas informações é de cunho pessoal, que diz respeito à própria pessoa ou à sua família, cuja divulgação 
pode ocasionar consequências prejudiciais à personalidade do indivíduo. Em 1983, a Corte Constitucional alemã, em uma decisão acerca da constitucionalidade de disposições da lei do censo, se fundamentou nos direitos constitucionais à dignidade humana e nos direitos de personalidade para delinear o direito à autodeterminação informativa como "a autoridade do indivíduo para decidir por si mesmo, com base na ideia de autodeterminação, quando e dentro de quais limites, informação acerca de sua vida privada pode ser comunicada a outros." (ROUVROY; POULLET, 2009, p. 45).

É nesse contexto que se coloca a necessidade de ampliação do conceito tradicional de privacidade, para incluir a necessidade de uma proteção mais ampla e eficaz da circulação dessas informações pessoais. Trata-se de conceder a cada indivíduo um poder real de controle sobre seus dados (KONDER, 2013, p. 374), visto que, na sociedade atual, a pessoa é representada por suas próprias informações, ou seja, as informações coletadas representam o próprio indivíduo, pois são essas que o definem. $\mathrm{O}$ conhecimento dos meios que possibilitam o controle sobre a circulação dessas informações e de quem as utiliza significa a possibilidade de cada indivíduo adquirir um poder sobre si mesmo.

Entre o final do século XIX e o início do século XX, a sociedade passou a ter consciência dos riscos decorrentes do progresso alcançado pela tecnologia, bem como da impossibilidade de detê-lo, visto que a capacidade de controlar os dados fornecidos ainda caminha em passos lentos, em desequilíbrio com a rapidez do progresso científico, e isso é resultado do número cada vez maior de informações fornecidas pelas pessoas para que obtenham determinados serviços.

A preocupação que surge é quanto ao destino dado a essas informações pelos gestores dos sistemas interativos, uma vez que esses 
serviços possibilitam uma série de usos secundários, como por exemplo, a criação de perfis, análise de preferências, propensões individuais e coletivas, que originam novas informações de interesse de terceiros, a quem aquelas podem ser cedidas para colocar à disposição das pessoas aquilo que lhes deseja ou thes serve, representando uma atividade de risco, que se concretiza, por exemplo, mediante a utilização indevida das informações, ou simplesmente pela sua utilização por terceiros sem o conhecimento e consentimento do titular dos dados.

$\mathrm{O}$ aumento desenfreado das informações coletadas pelas instituições públicas e privadas objetivam intervenções sociais por parte dos poderes públicos, bem como o desenvolvimento de estratégias empresariais pelas empresas privadas a fim de alcançar seus interesses e aumentar sua lucratividade. O que significa que a sociedade está sendo cada vez mais vigiada, assediada e, consequentemente, se tornando mais transparente e ausente de controle sobre os seus próprios dados.

$\mathrm{O}$ direito à proteção de dados é uma expressão de liberdade $\mathrm{e}$ dignidade e tem a ver com a proteção da própria personalidade. $\mathrm{O}$ que quer dizer que determinadas categorias de dados, especialmente os de natureza médica e genética, não podem ser utilizados para fins negociais; ao contrário, devem ser mantidas sob sigilo, sem qualquer ameaça de utilização de modo a transformar o indivíduo em objeto sob vigilância constante (RODOTÁ, 2008, p. 19).

Por outro lado, o direito de acesso efetivo aos dados fornecidos permite uma maior transparência da atuação dos organismos públicos e privados na coleta. Ou seja, o exercício desse acesso funciona tanto como um instrumento de transparência dessa atividade, visando à proteção da privacidade, quanto de limitação da circulação de determinadas informações. 
Restringir a coleta e a difusão das informações pessoais, no exercício do direito de defesa da privacidade, inclina-se especialmente sobre informações que são consideradas particularmente sensíveis, como as relacionadas à esfera da saúde, das opiniões, das questões sindicais e políticas e de orientação sexual, visto que a partir delas podem partir práticas discriminatórias, inclusive em ambientes de trabalho.

No âmbito do trabalho, a regulação de coletar informações dessa natureza decorre da necessidade de impedir condutas discriminatórias entre indivíduos, relacionadas ao comportamento do trabalhador dentro e fora do local de trabalho. No item seguinte serão discutidos os limites ao poder do empregador diante da necessidade de respeito aos direitos de personalidade do trabalhador.

\section{LIMITES AO PODER EMPREGATÍCIO EM DECORRÊNCIA DO DIREITO À PRIVACIDADE DO TRABALHADOR}

No âmbito do direito do trabalho, o progresso tecnológico e o acesso mais rápido a informações também tiveram um relevante papel, pois possibilitaram o uso de instrumentos informáticos pelo trabalhador, facilitadores da execução das atividades laborais, tornando o trabalho mais ágil por meio de tarefas que antes só podiam ser realizadas manualmente e com grande dispêndio de tempo. Com a tecnologia, o acesso a certas informações e o seu processamento possibilitaram maior produtividade e lucratividade para as empresas. Em contrapartida, essas ferramentas tecnológicas permitiram ao empregador um maior controle e vigilância sobre os empregados, desde o momento prévio à admissão no emprego à supervisão constante durante a vigência do contrato de trabalho.

Dessa nova realidade, diferentes conflitos surgiram. De acordo 
com Palm (2009, p 203), a privacidade do trabalhador deve ser respeitada, no ambiente de trabalho, no que concerne a três relações essenciais: com o empregador, com os colegas de trabalho e com os clientes. Diferente de relações casuais, no ambiente de trabalho as relações costumam se prolongar no tempo o que dá ainda maior relevância à privacidade no que concerne a certas informações. As informações constantemente buscadas pelo empregador, se utilizadas inadequadamente, são capazes de causar prejuízos, principalmente quando adentram em dados sensíveis do empregado, relacionados à sua orientação sexual, seu estado de saúde, sua opinião política, seu modo de vestir-se fora do local de trabalho e os seus momentos íntimos de lazer, sem que nenhuma dessas questões sequer influencie na atividade executada pelo empregado dentro da empresa. Ou seja, alcançam-se informações que dizem respeito unicamente à personalidade do trabalhador, violando a sua privacidade, sob o manto do exercício do poder empregatício. Dessa forma, surge um confronto entre o direito de privacidade do empregado e o poder diretivo do empregador. Questiona-se, portanto, se esse poder deve ou não sofrer limitações diante do conhecimento de toda e qualquer espécie de informação adquirida sobre o empregado.

Por ser espécie dos direitos da personalidade, que são direitos constitucionalmente garantidos e que pretendem resguardar a dignidade da pessoa em qualquer relação jurídica, inclusive a relação de emprego, o direito à privacidade é oponível ao empregador e deve ser por esse respeitado durante o vínculo empregatício. $\mathrm{O}$ direito à privacidade, todavia, não é absoluto, sofre limitações diante do poder diretivo do empregador, que objetiva garantir o bom funcionamento da empresa. A doutrina tem preferido se reportar de forma autônoma às dimensões do poder empregatício, que se dividem em poder diretivo, regulamentar, 
disciplinar e fiscalizatório (DELGADO, 2002, p. 608).

Pelo poder diretivo ou organizativo, o empregador distribui as funções, os cargos e a atividade da empresa, ou seja, organiza a sua estrutura interna. Acentua-se que o poder regulamentar para a doutrina dominante é uma expressão do poder diretivo, dado que é através de meios formais e informais que o poder diretivo se concretiza; já o poder disciplinar permite a punição àqueles trabalhadores que violam as normas do contrato de trabalho; e, por último, o poder fiscalizatório, também chamado poder de controle, que permite ao empregador verificar o exercício da atividade dos seus empregados, possibilitando um acompanhamento contínuo da prestação laboral e uma certa vigilância ao longo do espaço interno de trabalho.

Esse poder de controle se manifesta muitas vezes por instrumentos tecnológicos, como por exemplo, circuito interno de televisão, e-mails corporativos e acesso a redes sociais do trabalhador. E é importante tanto no âmbito econômico, para o desenvolvimento da atividade empresarial, quanto social, para a geração de empregos. Tanto o é que a fiscalização do trabalho é mais do que um direito, é também uma função da empresa. Entretanto, esse poder fiscalizatório não pode ser exercido de acordo com o julgamento do empregador. Há direitos expressos na Constituição Federal de 1988, em seu artigo $5^{\circ}$, que visam garantir o respeito e o bom desenvolvimento da personalidade de cada indivíduo. A proteção à liberdade e à dignidade da pessoa humana geram efeitos em todo e qualquer tipo de relação jurídica, por isso não podem ser restringidas a ponto de se admitir a violação da privacidade, intimidade, honra e imagem do trabalhador.

A Constituição Federal, ao estabelecer como fundamento da República Federativa do Brasil a dignidade da pessoa humana, 
repudia qualquer ato que agrida a liberdade, a igualdade e a integridade psicofísica, que são alguns dos princípios corolários da dignidade. Outrossim, os direitos da personalidade estão garantidos pelo princípio da dignidade e protegidos pela cláusula geral de tutela da pessoa humana.

Todavia, os instrumentos tecnológicos de informação, ao permitir o acesso desenfreado pelo empregador a dados sensíveis do trabalhador, têm causado sérios riscos e violações a esses princípios e direitos constitucionais, causando, como consequência, práticas discriminatórias dentro e fora do ambiente de trabalho. Nesse sentido, tem sido recorrente em seleções de emprego a busca prévia por características pessoais, opiniões políticas, orientação sexual, no perfil do candidato em redes sociais. Ou seja, o candidato é invadido na sua privacidade, em questões que muitas vezes não têm qualquer relação com a função no trabalho, sendo julgado e representado antes mesmo de uma análise profissional ao seu currículo.

É preciso que haja uma ponderação entre os interesses presentes na relação empregatícia, isto é, um ponto de equilíbrio para que o exercício do direito do empregador não viole os direitos de personalidade do empregado. Dessa forma, será possível identificar até onde o poder diretivo pode avançar para não restringir de forma desarrazoada os direitos de personalidade. Mesmo em uma situação específica no direito do trabalho: o emprego em organizações de tendência, há de se ponderar acerca da extensão do poder diretivo do empregador frente aos direitos de personalidade do trabalhador. Nesse caso, não se deve admitir uma restrição absoluta aos direitos de personalidade do trabalhador, inclusive no se refere à sua privacidade, em razão da ideologia, credo ou religião do empregador. A restrição deve ser razoável no sentido de questionar de que modo aspectos existenciais privados do trabalhador prejudicam de 
fato a organização (ALVES, 2012). Deve-se observar se aquele aspecto existencial do trabalhador contraria uma qualificação ocupacional de boa-fé, ou seja, uma exigência do empregador que fora do contexto de uma organização de tendência seria considerada discriminatória, mas que nesse caso se mostra necessária e extremamente gravosa de ser acomodada pelo empregador.

Apesar da ausência de preceitos jurídicos claros na seara trabalhista, as regras e princípios gerais são aptos a orientar o operador jurídico diante da violação de direitos da personalidade no caso concreto. Tanto o é que, ainda que em passos lentos, a ordem jurídica estatal tem manifestado preocupação quanto às violações do direito da personalidade no ambiente de trabalho, ao estabelecer, por exemplo, o Artigo 373-A da CLT $^{1}$ que veda revistas íntimas em trabalhadoras pelo empregador ou preposto.

Em 2016, entrou em vigor a Lei 13.271, que positivou a proibição de revista íntima de empregadas nos locais de trabalho, bem como de revista íntima em ambientes prisionais, com o fim de garantir

1 A lei 9.799 de 26.05.1999 incluiu na Consolidação das Leis do Trabalho o artigo 373-A, que traz vedações a práticas discriminatórias entre trabalhadores, bem como que violem direitos da personalidade. Senão vejamos: Art. 373-A. Ressalvadas as disposições legais destinadas a corrigir as distorções que afetam o acesso da mulher ao mercado de trabalho e certas especificidades estabelecidas nos acordos trabalhistas, é vedado: (Incluído pela Lei $\mathrm{n}^{\circ}$ 9.799, de 26.5.1999) I - publicar ou fazer publicar anúncio de emprego no qual haja referência ao sexo, à idade, à cor ou situação familiar, salvo quando a natureza da atividade a ser exercida, pública e notoriamente, assim o exigir; (Incluído pela Lei no 9.799, de 26.5.1999).

II - recusar emprego, promoção ou motivar a dispensa do trabalho em razão de sexo, idade, cor, situação familiar ou estado de gravidez, salvo quando a natureza da atividade seja notória e publicamente incompatível; (Incluído pela Lei n ${ }^{\circ}$ 9.799, de 26.5.1999) III - considerar o sexo, a idade, a cor ou situação familiar como variável determinante para fins de remuneração, formação profissional e oportunidades de ascensão profissional; (Incluído pela Lei ${ }^{\circ}$ 9.799, de 26.5.1999) IV - exigir atestado ou exame, de qualquer natureza, para comprovação de esterilidade ou gravidez, na admissão ou permanência no emprego; (Incluído pela Lei $\mathrm{n}^{\circ}$ 9.799, de 26.5.1999) V - impedir o acesso ou adotar critérios subjetivos para deferimento de inscrição ou aprovação em concursos, em empresas privadas, em razão de sexo, idade, cor, situação familiar ou estado de gravidez; (Incluído pela Lei $\mathrm{n}^{\circ}$ 9.799, de 26.5.1999) VI - proceder o empregador ou preposto a revistas íntimas nas empregadas ou funcionárias. (Incluído pela Lei $\mathrm{n}^{\circ} 9.799$, de 26.5.1999) Parágrafo único. O disposto neste artigo não obsta a adoção de medidas temporárias que visem ao estabelecimento das políticas de igualdade entre homens e mulheres, em particular as que se destinam a corrigir as distorções que afetam a formação profissional, o acesso ao emprego e as condições gerais de trabalho da mulher (Incluído pela Lei n ${ }^{\circ}$ 9.799, de 26.5.1999). 
e assegurar à mulher o direito ao trabalho sem ter, sucessivamente, sua privacidade violada. $\mathrm{O}$ art. $3^{\circ}$ da referida lei, direcionado à revista íntima em ambientes prisionais, foi vetado pela ex-presidente da república, uma vez que admitia a revista íntima nas prisões, além de permitir a interpretação de que todas as revistas seriam feitas por agentes do sexo feminino - tantos em homens quanto em mulheres. Portanto, além da previsão na Consolidação das Leis do Trabalho sobre vedação de revista íntima, a Lei 13.271/2016 reforçou a proibição dessa prática discriminatória e violadora da intimidade da empregada nos locais de trabalho.

A Lei estabeleceu, ainda, penalidade, decorrente da realização de revista íntima em empregadas e clientes das empresas privadas, órgãos e entidades da administração pública, direta e indireta, de multa de vinte mil reais ao empregador, revertidos aos órgãos de proteção dos direitos da mulher, e, em caso de reincidência, multa em dobro daquele valor, independentemente da indenização por danos morais e materiais e sanções de ordem penal.

Por outro lado, a Organização Internacional do Trabalho - OIT traz previsão normativa expressa de repúdio a atos discriminatórios no ambiente de trabalho. A Convenção $n^{0} 111$ da OIT, ratificada pelo Brasil em 26 de novembro de 1965, no seu artigo $1^{\circ}$, apresenta um rol de formas de discriminação que considera como ato discriminatório qualquer distinção, exclusão ou preferência que vise destruir ou alterar a igualdade de tratamento em matéria de emprego ou profissão. O Brasil, porém, mesmo tendo ratificado a referida Convenção, não a observa em sua plenitude, uma vez que o acesso a informações de cunho privado do trabalhador é fator responsável por condutas discriminatórias no ambiente de trabalho, expressamente vedadas pela norma internacional. 
Em uma tentativa de normatização do tema, no ano de 2008, durante o XIV Congresso Nacional da Magistratura da Justiça do Trabalho, foi aprovado o enunciado sobre banco de dados e intimidade informática no trabalho:

Os bancos informatizados de dados permitem traçar o perfil ideológico, racial, sexual ou psicológico do trabalhador, podendo vulnerar o direito à intimidade ou ensejar práticas discriminatórias na empresa. $\mathrm{O}$ direito à intimidade informática do trabalhador está fundado nos princípios da finalidade e autodeterminação informativa. O primeiro impõe a conexão entre a informação cadastrada e um interesse empresarial legítimo, e o segundo pressupõe o consentimento inequívoco do trabalhador e a possibilidade de vindicar a alteração de dados, quando errôneos ou desatualizados (DINIZ, 2008).

A doutrina tem demonstrado especial atenção ao estudo da privacidade dos trabalhadores em razão das consequências geradas pelo uso de telefones celulares fornecidos pelo empregador, comunicação via internet à sua residência e todos os outros instrumentos eletrônicos que violam a vida privada do trabalhador em seus momentos íntimos e de convívio familiar, mas ainda são insuficientes e ineficazes as ferramentas de proteção efetiva do direito de privacidade do empregado, e, consequentemente, a prática de atos discriminatórios ainda estão presentes no cotidiano das relações de trabalho.

\section{A DISCRIMINAÇÃO NAS RELAÇÕES DE TRABALHO DECORRENTE DA COLETA DE DADOS SENSÍVEIS}


Como examinado, portanto, o acesso a dados sensíveis do trabalhador e de candidatos a vagas em empresas é uma prática cada vez mais recorrente entre empregadores, que se utilizam de instrumentos tecnológicos e informatizados para controlar, vigiar e buscar informações novas sobre os trabalhadores.

Essas informações são coletadas e utilizadas de diversas formas, sob inúmeros fundamentos, como por exemplo, garantir uma maior segurança para a empresa, preservar a sua imagem, entre outras tantas justificativas. Porém, a vigilância incessante sobre a vida privada do empregado possibilita ao empregador, sob o argumento de estar respaldado no seu poder diretivo, utilizar as informações pessoais coletadas para práticas discriminatórias e abusivas, que ferem sobremaneira os direitos de personalidade do trabalhador.

Há dois diferentes níveis de tratamento aos dados do trabalhador, um que pode ser utilizado na fase pré-contratual, no decorrer da seleção para o emprego, em que o empregador realiza o tratamento de dados de identificação, através de currículos, perfil psicológico, dados de saúde e de registros criminais, por exemplo. E outro, durante o contrato de trabalho, em que os dados do trabalhador são utilizados para aferir a sua produtividade, seu estado de saúde e a observância do cumprimento das regras estabelecidas pela empresa (CASTRO, 2002, p. 28-29).

Com efeito, tem sido usual nas empresas, durante a fase de seleção, a aplicação de testes genéticos, exames toxicológicos, investigação sobre questões pessoais em facebook e outras redes sociais, questionamentos sobre orientação sexual, opinião política, dentre outros. Todavia, a jurisprudência tem considerado abusiva muitas destas práticas, pois representam uma presunção de discriminação, uma vez que determinadas informações em nada interferem na condição de um 
bom profissional. Apenas aquelas que versem sobre a vida profissional do candidato, como por exemplo, experiências anteriores, diplomas e certificados, devem ser realizadas.

Atos discriminatórios, decorrentes do conhecimento dessas informações, podem ocorrer em ambos os momentos referidos, não somente pela invasão de privacidade, mas também pela eventual divulgação desses dados após a seleção. Por essa razão, os dados pessoais de candidatos não selecionados devem ser mantidos apenas enquanto durar o processo. Apesar de não haver uma previsão expressa sobre o assunto, se discute sobre a possibilidade de se admitir a aplicação da prescrição bienal trabalhista para manutenção desses dados, ou seja, surge para o candidato o direito ao esquecimento, referente aos seus dados pessoais fornecidos durante a seleção, após o transcurso de dois anos.

Durante a manutenção do contrato de trabalho, a discriminação pode ultrapassar a relação entre empregado e empregador, ocorrendo, inclusive, por colegas de trabalho, gerando o afastamento do trabalhador do convívio social e, em casos extremos, cria-se uma oportunidade para o assédio moral no trabalho. Vê-se, portanto, que em qualquer das hipóteses há uma violação ao princípio da dignidade humana se não houver um limite para utilização daquelas informações.

Essa violação gera o direito à indenização por dano moral. Dessa forma, o empregado pode pleitear judicialmente uma indenização pela violação à sua privacidade. É contumaz na jurisprudência dos tribunais trabalhistas, o ajuizamento de ações que tratam de situações de discriminação, seja pela orientação sexual, por opiniões políticas ou religiosas, que buscam a devida reparação pela violação à imagem, a honra e a dignidade do trabalhador.

Ainda há muitos trabalhadores que suportam calados atos 
discriminatórios no ambiente de trabalho, geralmente por ser aquele emprego a fonte de sustento da família, e por medo da demissão, diante da dificuldade em encontrar um novo posto de trabalho. O trabalhador termina por se encontra psicologicamente condicionado na luta pelos seus direitos.

Essas ações, normalmente, são ajuizadas apenas quando o empregado é demitido pela empresa, ou quando as consequências da violação aos direitos da personalidade atingem o trabalhador de tal maneira que o impede de se manter no trabalho. $\mathrm{E}$ as consequências dos atos discriminatórios, a depender da situação, podem causar graves problemas que comprometem o desenvolvimento da sua personalidade.

O leque de direitos fundamentais nas relações de trabalho é bastante amplo, abrangendo desde o princípio da dignidade da pessoa ao respeito à honra, à intimidade e à privacidade, que buscam salvaguardar os aspectos mais íntimos do indivíduo, tutelando, por conseguinte, a sua personalidade, e que devem ser respeitados pelo empregador no âmbito da relação de emprego, visto que estão além do seu poder diretivo. Com esse fundamento normativo, são três as respostas possibilitadas pela lei ao trabalhador em decorrência de atos discriminatórios no ambiente de trabalho. A primeira definida como "despedida indireta", prevista no art. 483 da CLT, em que se pleiteia, por meio do ajuizamento de uma ação, o reconhecimento da falta grave cometida pelo empregador e o recebimento de todas as verbas rescisórias. A segunda é o ajuizamento de uma ação para reintegração no trabalho, desde que não haja incompatibilidade entre as partes para prosseguimento da relação empregatícia, no caso do empregado ter sido demitido, e sendo o obreiro portador de algum tipo de estabilidade ou garantia de emprego. Por último, o ajuizamento de uma ação buscando unicamente o dano moral decorrente do ato 
discriminatório sofrido, que também pode ser cumulado com as hipóteses anteriores.

Contudo, vê-se que ainda é necessária uma eficaz proteção à privacidade do trabalhador, que alcance desde o acesso à divulgação dos dados sensíveis coletados. O que quer dizer, portanto, que a anuência do trabalhador para tomada de conhecimento dessas informações pela entidade empregadora não importa obrigatoriamente na sua divulgação, ou seja, não se estende à possibilidade de revelá-los a terceiros, mas é preciso seu consentimento e a possibilidade de controlá-las.

\section{CONCLUSÃO}

O conceito tradicional de privacidade, sob a influência da tecnologia, evoluiu. Por um lado, a partir das novas tecnologias, as informações dos indivíduos foram sendo cada vez mais acessadas em decorrência do surgimento de novos instrumentos de coleta de dados; por outro, o direito de acesso efetivo aos dados fornecidos permite uma maior transparência da atuação dos organismos públicos e privados na coleta. Ou seja, o exercício desse acesso funciona tanto como um instrumento de transparência dessa atividade, visando à proteção da privacidade, quanto de limitação da circulação de determinadas informações.

Essas transformações ocasionaram um apelo maior à privacidade, mas não sob uma lógica proprietária, de defesa da esfera privada contra as invasões exteriores, e sim da possibilidade de indivíduos e grupos controlarem suas próprias informações de forma integrada.

As mudanças tiveram repercussão em todos os tipos de relações jurídicas, inclusive, nas trabalhistas. Com a tecnologia, o acesso a certas informações e o seu processamento possibilitaram maior produtividade 
e lucratividade para as empresas. Em contrapartida, essas ferramentas tecnológicas permitiram ao empregador um maior controle e vigilância sobre os empregados, desde o momento prévio à admissão no emprego à vigilância constante durante a vigência do contrato de trabalho.

Os empregadores passaram a se utilizar de ferramentas tecnológicas para facilitar o desenvolvimento estrutural e produtivo da sua empresa, mas também para ter acesso a todo tipo de informação sobre o trabalhador, buscadas desde a fase pré-contratual, de seleção do emprego, como durante o vínculo empregatício, inclusive sobre os seus dados sensíveis, que em nada definem sua aptidão profissional, como as relacionadas à esfera da saúde, das opiniões, das questões sindicais e políticas e de orientação sexual, visto que a partir delas podem partir práticas discriminatórias.

$\mathrm{O}$ direito à privacidade passou a sofrer com maior frequência violações em decorrência dos instrumentos tecnológicos facilitadores de acesso a dados pessoais do trabalhador, sob a falsa crença de estar o empregador agindo de acordo com o seu poder empregatício, decorrente da relação de emprego, gerando graves consequências ao desenvolvimento da personalidade do indivíduo.

Dessa forma, a jurisprudência recente tem condenado as empresas que praticam atos discriminatórios a pagamento de indenizações, sob o fundamento de que a privacidade, quando violada, gera direito a dano moral, por ser ela um direito da personalidade.

A legislação internacional ainda não tem um tratado internacional específico sofre proteção de dados pessoais no local de trabalho, mas possui expressa previsão sobre o direito a não-discriminação e à privacidade, que devem ser respeitadas pelo Brasil, visto que o país ratificou a Convenção no 111 da OIT, que dispõe sobre o assunto. 
A legislação nacional possui expressa previsão na Constituição Federal, em seu art. $5^{\circ}$, que garante proteção aos direitos da personalidade. A legislação trabalhista, todavia, ainda é omissa sobre o assunto, mas, a passos lentos, tem criado mecanismos de combate à discriminação e aos direitos da personalidade do trabalhador.

Por fim, conclui-se que ainda não é possível garantir uma tutela eficaz aos dados sensíveis do trabalhador nas relações empregatícias. É necessário estabelecer diretrizes para o tratamento das informações coletadas considerando o poder empregatício do empregador, para que esse poder não seja exercido de forma a violar o direito de privacidade do trabalhador, respeitando, portanto, os seus dados sensíveis.

\section{REFERÊNCIAS}

ALVES, Ricardo de Paula. Vida pessoal do empregado, Liberdade de expressão e direitos fundamentais do trabalhador - considerações sobre a experiência do direito francês. Doutrinas essenciais de direito do trabalho e da seguridade social, São Paulo, v. 3, n. 1, p.871-891, set. 2012.

CASTRO, Catarina Sarmento e. A proteção dos dados pessoais dos trabalhadores. Questões laborais, Lisboa, n. 19, p. 27-60, 2002.

DELGADO, Mauricio Godinho. Curso de direito do trabalho. São Paulo: Ltr, 2002.

DINIZ, Ana Paola Santos Machado. Banco de dados e intimidade informática no trabalho. 2008. Disponível em: $<\mathrm{http}: / / \mathrm{www}$. conjur.com.br/2008-mai-31/anamatra_aprova_47_teses_justica trabalho?pagina=2>. Acesso em: 19 jan. 2017. 
KONDER, Carlos Nelson. Privacidade e corpo: convergências possíveis. Pensar, Fortaleza, n. 2, p. 354-400, maio/ago. 2013.

PALM, Elin. Privacy Expectations at Work-What is Reasonable and Why? Ethical theory and moral practice, v. 12, n. 2, p. 201215, 2009. Disponível em: <http://resolver.scholarsportal.info/ resolve/13862820/v12i0002/201_peawiraw>. Acesso em: 17 jan. 2017.

RODOTÀ, Stefano. A vida na sociedade da vigilância: a privacidade hoje. Rio de Janeiro: Renovar, 2008.

ROUVROY, Antoinette; POULLET, Yves. The right to informational self-determination and the value of self-development: reassessing the importance of privacy for democracy. In:

GUTWIRTH, Serge et al. (Ed.). Reinventing data protection? The Netherlands: Springer Netherlands, 2009. p. 45-76.

WARREN, Samuel; BRANDEIS, Louis. The right to privacy. Harvard Law Review, Harvard v. 4, n. 5, p. 193, Dec. 1890.

Como citar: COSTA, Andréa Dourado; GOMES, Ana Virginia Moreira. Discriminação nas relações de trabalho em virtude da coleta de dados sensíveis. Scientia Iuris, Londrina, v. 21, n. 2, p. 214-236, jul. 2017. DOI: $10.5433 / 2178-8189.2017 \mathrm{v} 21 \mathrm{n} 1 \mathrm{p} 214$. ISSN: 2178-8189.

Recebido em: 19/01/2017

Aprovado em: 22/05/2017 